\title{
Living Community Visualisation: A case study of school districts in Hsinchu
}

\author{
Fang-Yu Chen \\ National Chiao Tung University \\ 1001 University Road, Hsinchu 300, \\ Taiwan \\ fangyu903@arch.nctu.edu.tw
}

\author{
Tien Ling \\ National Chiao Tung University \\ 1001 University Road, Hsinchu 300, \\ Taiwan \\ tienling@arch.nctu.edu.tw
}

\author{
Nai-Chun Chen \\ National Chiao Tung University \\ 1001 University Road, Hsinchu 300, \\ Taiwan \\ naichunncku2018@gmail.com
}

\section{INTRODUCTION}

It is common to organise information by spatial analysis in architecture. For example, GIS (Geographic Information System) combines all kinds of data into maps. Due to the rapid development of science and technology, it is easier for us to get open data and analyse cities.

The division of districts limits our data sources, but the living community of the residents is actually not limited to this boundary. If we only analyse the city from the administrative district's point of view, we can't fully demonstrate the actual living community of residents.

Our research aims to analyse cities in a way that is different from the traditional administrative division. In Taiwan, the city is divided by neighbours. The school district is a different division from the administrative division; the school is the centre, which is divided according to population, transportation, community, cultural environment, administrative area, and school distribution, for families with school-age children. It is an important factor to choose where they live.

In our research, we regard the school district as a way to divide the city, which reflects the living community, and we provide a visualisation of it with an interactive installation.

\section{THE BOUNDARY OF THE CITY}

Lynch (1960) pointed out that the residents' image of the city is based on the five elements: paths, edges, districts, nodes, and landmarks. We can see that people's image of city boundaries is not relative with the actual city administrative division.

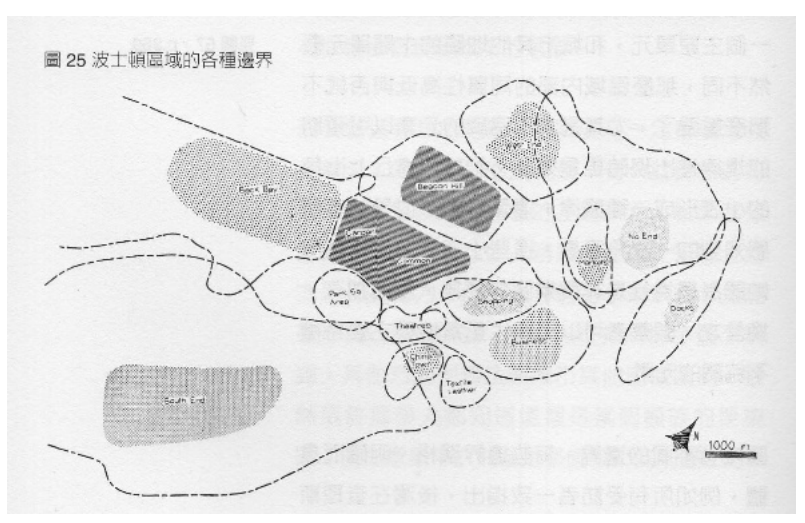

Figure 1: The Image of the City, p.122.

There is some discrepancy between the image of residents and the administrative division. The residents' living ways probably are not visible in our traditional administrative boundaries.

In the design research of the department of architecture, Tunghai University, Taiwan (Tien Ling 2017), this project takes Dadu mountain as the research object. Dadu mountain is a plateau in Taichung, Taiwan. It is not a traditional administrative district, but a new boundary created by terrain and residents' cognition. In terms of traditional districts, it covers nine administrative districts.

From the perspective of residents and tourists, this area is usually called "Dadu mountain" instead of the traditional administrative district. One of the reasons is that people's activities and daily routines are relative to "Dadu mountain". Therefore, in this case, the boundary of Dadu mountain is redefined under the division of the traditional administrative district.

In this project, population estimates have been derived from the average population area under the district. In our research, we use this research as a 
reference for school district division and population estimation.

In Taiwan, we observe that elementary school is an institution with an open boundary, often dispatched to act as a polling place, and an examination centre by the government. It is also used on a daily basis as a playground by residents.

We regard elementary school as the centre of community activities, and take it as the starting point to discuss the living community by the school district.
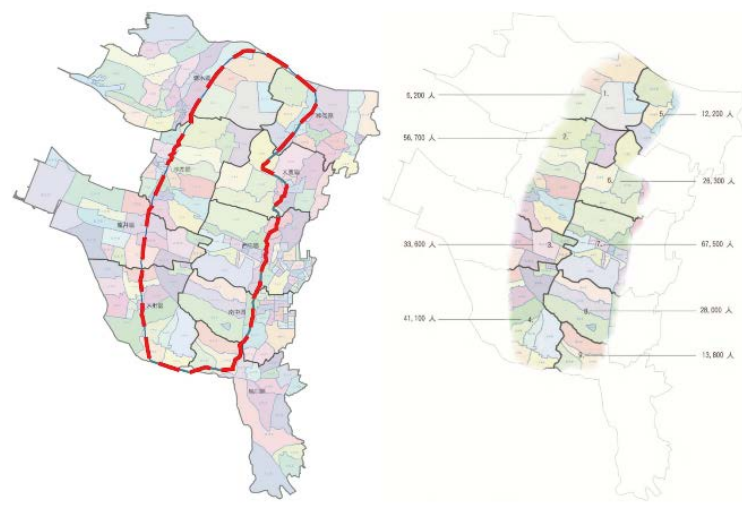

Figure 2: Dadu mountain districts.

\section{SCHOOL DISTRICTS}

In this research, we take Hsinchu city, Taiwan as the target city. With the development of Hsinchu Science Park, Hsinchu city has the highest income in Taiwan. The total population in Hsinchu is 445,990 . After analysing the population structure, we find that the school-age population is increasing which shows the high demand for the schools in Hsinchu city. Therefore, We regard schools as an important space for this city.

We use government open data as the source of our analysis.

To correspond to the meaning of the school district living community, we extracted the relative data as the reference for the research, such as temple, market, hospital, park, etc.

\section{INTERACTIVE MAPPING OF SCHOOL DISRICTS}

Recent advances in public sector open data and online mapping software are opening up new possibilities for interactive mapping in research applications (Smith 2016).
With the progress of science and technology, people combine maps and information frequently.

We made the school district puzzle of Hsinchu city with MDF and processed the internal information of each school district, including the information with the school district, the school district area and the location of the elementary school.

We visualise the information using Processing and connect the information to Arduino. It helps us to scan the action of users. The information of school district on the projection changes when users pick up the different parts of the map. First, it displays the basic information in the school district, such as the amount of population, hospital, parks, populations and temples. On the other hand, it also shows the average data of above objects calculated based on the area and population.

We can see the differences between each school district through this interactive installation art.

It corresponds to the actual state of the Hsinchu living community and shows the differences between the boundary of the traditional administrative district and the living community.

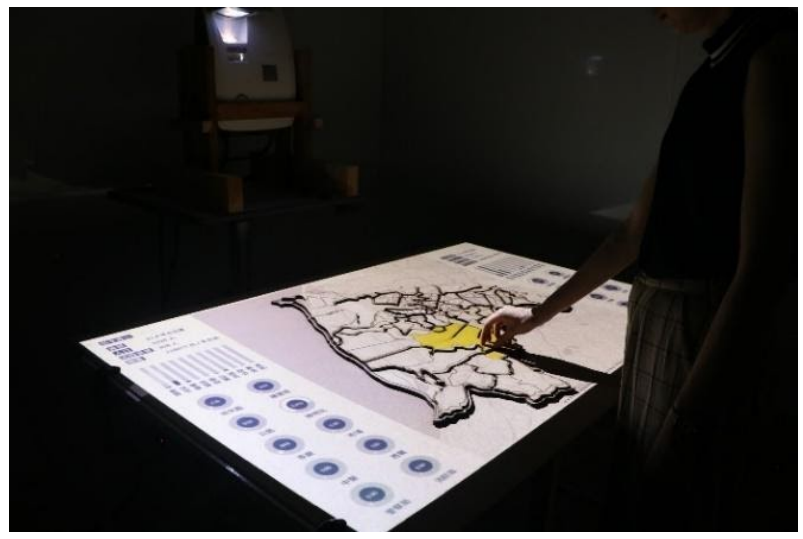

Figure 3: Interactive installation in school districts of Hsinchu, Taiwan.

\section{REFERENCES}

Ling T. (2017) Da-Du Design. Tunghai University, Taiwan.

Lynch, K. (1960) The Image of the City, MIT Press. Cambridge, MA.

Smith, D. A. (2016) Online interactive thematic mapping: Applications and techniques for socioeconomic research. Computers, Environment and Urban Systems, 57, 106-117. 